\title{
Function of the upper tangle in webs of young Leucauge argyra (Araneae: Tetragnathidae)
}

Author(s) :Emilia Triana-Cambronero, Gilbert Barrantes, Erica Cuyckens, and Andrés Camacho

Source: Journal of Arachnology, 39(3):519-522. 2011.

Published By: American Arachnological Society

DOI:

URL: http://www.bioone.org/doi/full/10.1636/Hi11-36.1

BioOne (www.bioone.org) is a nonprofit, online aggregation of core research in the biological, ecological, and environmental sciences. BioOne provides a sustainable online platform for over 170 journals and books published by nonprofit societies, associations, museums, institutions, and presses.

Your use of this PDF, the BioOne Web site, and all posted and associated content indicates your acceptance of BioOne's Terms of Use, available at www.bioone.org/page/terms_of_use.

Usage of BioOne content is strictly limited to personal, educational, and non-commercial use. Commercial inquiries or rights and permissions requests should be directed to the individual publisher as copyright holder. 


\title{
SHORT COMMUNICATION
}

\section{Function of the upper tangle in webs of young Leucauge argyra (Araneae: Tetragnathidae)}

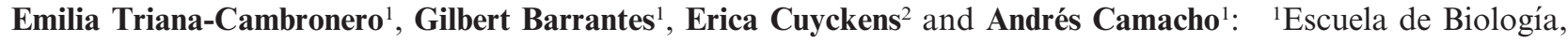 \\ Universidad de Costa Rica, Ciudad Universitaria Rodrigo Facio, San José, Costa Rica. E-mail: emit773@gmail.com; \\ ${ }^{2}$ CONICET, Mendoza 2, Salta 4400, Argentina
}

\begin{abstract}
Ontogenetic changes in web structure occur in many spiders of different families, but the functional adaptation of differences in web structure is unknown for most species. We describe the ontogenetic changes in web structure of Leucauge argyra (Walckenaer 1842) and test the function of these differences in webs of spiderlings. Webs of early instar spiders have tangles above the orb web that vary from relatively dense to a single thread, from which some threads extend downward, connecting the tangle to the hub of the orb web. The number of threads of the tangle decreases as spiders grow, and in webs of late instars, the tangle is absent. Our experimental results indicate that the tangle and connecting threads increase the stability of the web, possibly reducing the probability of spiral threads sticking to each other with web movements.
\end{abstract}

Keywords: Web structure, ontogenetic changes, web tangle, orb web

Change in web structure through successive instars is a pattern found in many spiders of different families (at least 21 species of 10 different families: see Eberhard et al. 2008), and some of these ontogenetic changes are substantial (Eberhard 1985; Barrantes \& Madrigal-Brenes 2008). However, with few exceptions, there has been no functional adaptation associated with these intraspecific differences in web structure between webs of young and adult spiders for most species. To our knowledge, the functional significance of ontogenetic changes in web architecture has been described only for Clitaetra irenae Kuntner 2006 (Kuntner et al. 2008a) and Nephila clavipes (Linneaus 1767) (Higgins 1992). Webs of C. irenae increase vertically in older spiders, as a possible adaptation to an arboricolous life style, as well as increase their hub eccentricity, possibly to optimize prey capture (Masters and Moffat 1983; Kuntner et al. 2008a, b). In $N$. clavipes, the density and proportional size of the tangle decrease as the spider grows as a consequence of reduction in predation risk (Higgins 1992).

Spiders of at least five families add tangles to their orb webs: Uloboridae, Mysmenidae, Nephilidae, Tetragnathidae, and Araneidae. There are several possible explanations for the function of tangles associated with orbicular webs. One is that the tangles serve as a mechanical barrier to protect the spider against flying predators (Comstock 1912; Robinson \& Robinson 1973; Higgins 1992) or parasites (Robinson \& Robinson 1973). Two other possible functions are that the tangles prevent escape of large prey (Hingston 1992) and act as support to strengthen the web (Lubin 1975). Only Higgins (1992) provides strong, though correlative, evidence that supports the anti-predator function of this structure, and Lubin (1975) provides correlative data that seems to support the web-strengthening hypothesis, but to our knowledge, none of these hypotheses has yet been tested experimentally.

The web of a Leucauge argyra (Walckenaer 1842) early instar has an upper tangle with threads connecting it to the hub and occasionally another tangle below the orb web, but these tangles are absent in webs of adult spiders. The upper tangle consists of a few threads that cover only a narrow section across the middle of the orb, contrary to the three-dimensional orb-like tangles or barriers in some nephilids that cover the entire dorsal and/or ventral side of the webs (Kuntner et al. 2008b). We specifically tested 1) whether the tangle above the orb web and the threads that connect this structure to the hub prevents the orb web striking the vegetation below it and 2) if the function of the tangle is to give stability to the orbicular section of the web, reducing web deformation and the probability of sticky spiral threads collapsing with air movement (these hypotheses may not be mutually exclusive).

We made field observations and experiments in a plantation of African oil palm (Elais guineensis L.) in Parrita, Puntarenas Province, Costa Rica $\left(09^{\circ} 30^{\prime} \mathrm{N}, 84^{\circ} 10^{\prime} \mathrm{W}\right.$, elev. $\left.10 \mathrm{~m}\right)$. To test the first hypothesis, we measured the distance of the hub of the orb web to the nearest substrate below in 21 webs of young spiders with upper tangles. This distance was later compared with the total hub displacement: distance after disconnecting the hub from the upper tangle plus its displacement distance after disconnecting it and blowing a constant perpendicular air current through the web (see below).

To test the second hypothesis, we constructed a three-sided cardboard shield $(30 \times 60 \times 30 \mathrm{~cm}, 40 \mathrm{~cm}$ high $)$ with black fabric (for better contrast with the web) attached to the central wall, and a ruler attached to the fabric. We placed this retreat around each web in the field to block uncontrolled natural breezes. We then applied an air current at a constant speed $(0.03 \mathrm{~m} / \mathrm{s})$ using a $9 \mathrm{~V}$-battery fan (Max Flow Enterprise Co., Ltd.) placed $14 \mathrm{~cm}$ above the center of the orb web, simulating a perpendicular breeze to the plane of the web. For each of 25 manipulated webs, we measured three variables: 1) downward displacement of the hub of the unmodified web when blown with the fan; 2) displacement of the hub when threads connecting the hub to the tangle above were cut (the spider was present in the hub when threads were cut);3) displacement of the hub when blown with the fan, after cutting the attachments to the tangle. We measured total body length of all 25 spiderlings to later test for a correlation of body length with web displacement.

We additionally measured the extensibility of two (occasionally one) $1 \mathrm{~cm}$ long segments of anchor threads in 20 webs with upper tangles of young spiders (different from the ones used for the other experiments) and of six webs of adult females. We attached each segment to pieces of double-sided sticky tape that had previously been attached to the jaws of a mechanical calliper as in Opell et al. (2008); a second piece of tape was placed on the threads to secure them. We then slowly separated the jaws of the calliper (ca $1 \mathrm{~mm} / \mathrm{s}$ ) to elongate threads until they broke. We measured extensibility as a proportion of the total extension relative to the initial thread length. When we measured two segments from the same web, their values were averaged. We collected and raised, in captivity, to adulthood two young spiders with tangled webs to confirm species identity and deposited these specimens in the Museo de Zoología, Universidad de Costa Rica. 

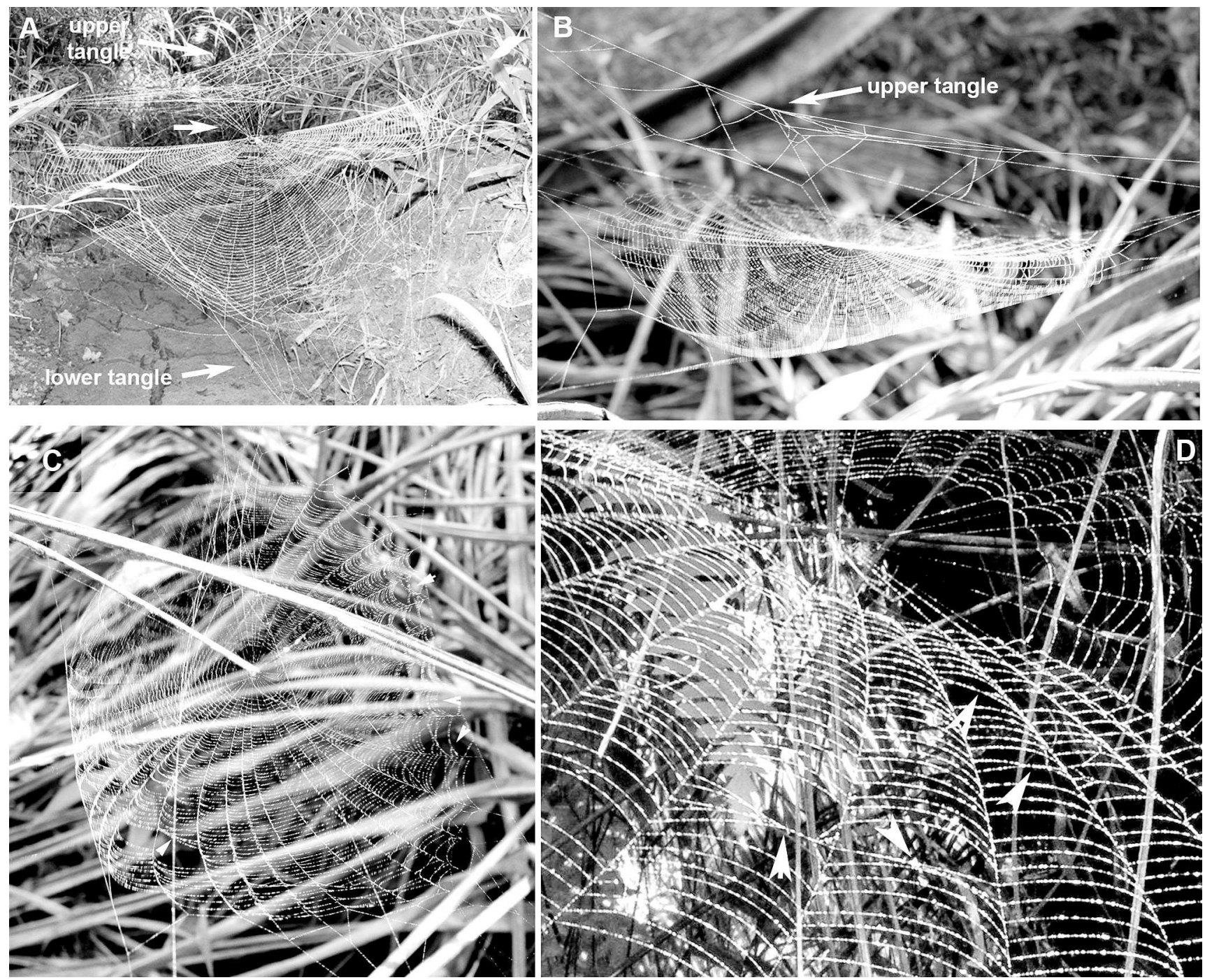

Figure 1.-Web characteristics of young Leucauge argyra. A. Web of a small spiderling with relatively dense tangle and numerous threads connecting the tangle to the hub of the orb web below. Part of the lower tangle with some threads attached to the substrate below is shown. B. Web of an older instar spiderling with a reduced tangle and few threads connecting the tangle to the hub of the orb web below. C. Web with radii and spiral threads deformed by a weak breeze in the field. D. Section of a spiderling web showing some spiral threads collapsed (white arrows).

Webs of L. argyra show clear ontogenetic changes. Adult females spin typical orb webs in horizontal planes $\left(0-20^{\circ}\right)$ without additional silk structures. They build them in open spaces, using exposed twigs and leaves on the herbaceous layer to attach the anchor threads. In contrast, early instar spiderlings (first instar out of the egg sac, recognized by their whitish abdomens, to possibly fourth instars, based on size) spin tangle structures above the horizontal orb webs (Figs. 1A, B). The tangle varies from a relatively dense, narrow tangle, to a few threads just a few $\mathrm{mm}$ above the orb. Several threads connect the hub to the tangle above. The tangle above the orb seems to be denser in younger spiderlings (Fig. 1A). In some webs, there is also a tangle of sparse threads that connect the web frame with the substrate below (Fig. 1A). Webs of early instars are constructed within dense herbaceous vegetation, often occupying small spaces among grass leaves.

Our results indicate that these tangles above the orb webs of early instar spiders serve to support the entire orb web. The distance between the orb webs and the nearest substrate below was much larger (mean $=12.09 \pm$ $11.73 \mathrm{~cm}, n=21$ ) than the total distance displaced by the webs after we disconnected them from the tangle $(4.02 \pm 1.58 \mathrm{~cm}$; $t$-test comparing both distances: $t_{40}=3.12, P<0.005$ ). The total distance included both the distance of displacement of the hub when disconnected from the tangle and the distance of displacement when blown after disconnected. Webs of young spiders displaced between $1 \mathrm{~cm}$ to $3.5 \mathrm{~cm}$ (mean $=1.6 \pm 0.94 \mathrm{~cm}, n=25$ ) downward after we disconnected the upper tangle from the orb web. This distance differed significantly from zero (no effect on threads in supporting the web; one sample t-test: $\left.t_{24}=8.59, P<0.00001\right)$, but displacement distance was not correlated with spider size $(r=0.49, P=0.82)$.

When we blew perpendicular air current on the webs after we disconnected the upper tangle, all but two of these webs displaced further down $($ mean $=2.4 \pm 0.9 \mathrm{~cm}, n=25)$ than intact webs with the same air current (mean $=1.4 \pm 0.8 \mathrm{~cm}, n=25$; paired $t$ test: $t_{24}=$ $6.12, P<0.00001$; Fig. 2). A possible explanation for the two webs in which displacement was less after disconnecting them from the upper tangle is that anchor lines of webs of young spiders can often be attached to grass blades that seem to be under some tension. Thus, when we disconnected the webs from the upper tangle, tension on the orbs may have increased and so reduced the downward displacement. Extensibility of anchor threads was similar between webs of young spiders and those of adult females $(1.88 \pm 1.46$ vs. $1.40 \pm 0.66$; MannWhitney $U=51.0, P=0.60, n=26$ ). 


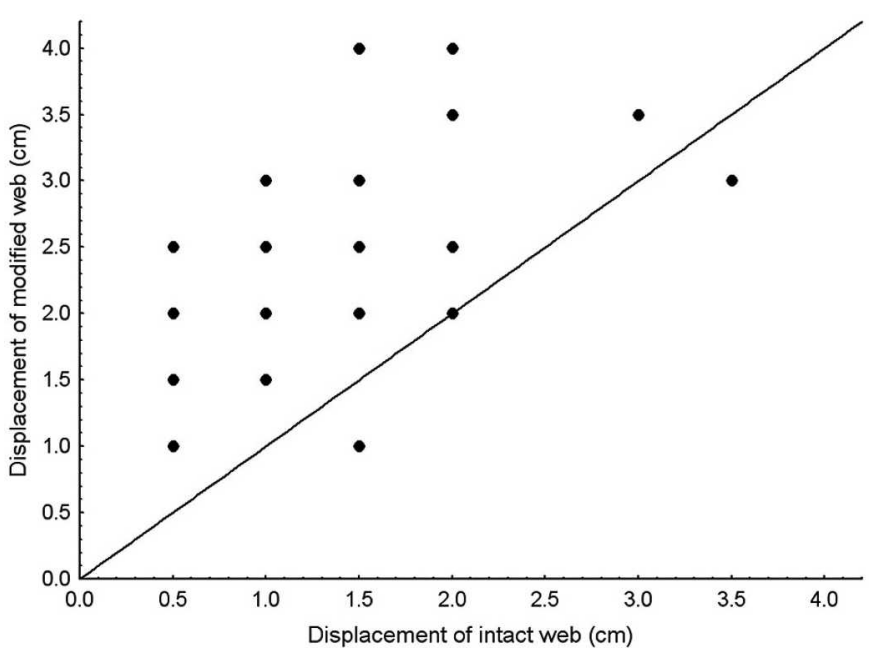

Figure 2.-Difference in displacement caused by a constant air current perpendicular to web plane, between intact webs (attached to the upper tangle) and the same webs after disconnecting them from the upper tangle. Dots above the line represent webs where displacement was larger after cutting the connecting threads. Line indicates equal effect of air current on intact and modified webs.

Despite young spiders constructing their webs among dense vegetation, the distance from the orb web to the nearest substrate below was large enough to prevent the orb web from contacting vegetation as it moved downward, even after the web was disconnected from the upper tangle. Therefore, our results do not support the hypothesis that the function of the upper tangle is to prevent the orb web from striking vegetation below.

Yet, webs of young L. argyra are slack. Under a nearly imperceptible breeze, the webs of young spiderlings buckle, the radii bending toward the wind's current trajectory and the spiral threads oscillating (Figs. 1C, D). Low tension of spiral threads makes webs good traps for retaining prey. Lower tension of these threads allows more kinetic energy to dissipate with the prey's impact (Eberhard 1990), but also make them susceptible to collapse in a weak breeze.

Damages of this type on the orb web are expected to reduce interception and retention of prey (Blackledge \& Zevenbergen 2006). Hence, we conclude that the upper tangle serves as support for the whole orb web, allowing the spiderling to construct a well adapted trap to retain prey. The tangle likely reduces web deformation, which in turn may at least partially prevent sticky threads from adhering (Figs. 1C, D). A possible advantage of the stabilization of the web provided by the upper tangle is the reduction in radial stress and damage. This is important since strong winds could cause mechanical yield in radial threads, and thus will greatly reduce their ability to dissipate kinetic prey energy (Harmer et al. 2011).

We did not test the function of the lower tangle. This tangle consists of sparse threads that connect the frame of only some spiderling's webs to the substrate below (Fig. 1A). Thus, it is possible that this tangle gives additional support to the orb web and some protection against predators and parasitoids attacking spiders from below, a function that may also be possible for the upper tangle.

We also recorded ontogenetic changes in webs of $L$. argyra that occur mainly on the structure of the tangle. The complexity of the tangle and the number of threads that connect the tangle to the hub of the orb web below decrease as the spider grows. Tangles change from a relatively dense tangle with many connecting threads (up to 17) in very small spiderlings (Figs. 1A, B), to a sparse tangle composed of few threads in older instars (in two occasions the tangle was composed of a single thread with three connecting threads), to its complete absence in webs of adult females (not a single web of adult females had a tangle above it, $n>300$ webs).
The extensibility of the anchor threads serves to absorb and dissipate some of the kinetic energy of a flying insect or the stress caused by wind currents (Denny 1976; Blackledge \& Hayashi 2006). Webs of both early instar and adult L. argyra have similar extensibilities. Casual observations under a dissecting microscope suggest that the thickness of the anchor threads increases in the webs of older instar spiders. However, as the diameter of the anchor threads increases, more energy is needed to extend a thread the same distance. Therefore, such thicker threads in older instars provide more support against orb deformation, reducing the need for the upper tangle.

We here present the first experimental evidence of the possible function of the web design of first instar spiders. We also describe the ontogenetic changes in the web design of $L$. argyra. These changes are consistent with the general ontogenetic pattern documented for a large number of spider species in different families. Furthermore, in most species in which the ancestral-descendant evolution of webs can be traced, webs of first instar spiders nearly always represent ancestral characters (Japyassú \& Ades 1998; Eberhard et al. 2008; Barrantes \& Eberhard 2010). However, it is yet untested whether these ontogenetic changes mirror phylogenetic changes in web structure in this lineage (i.e., whether the silk tangle is an ancestral or derived character within the Orbiculariae).

\section{ACKNOWLEDGMENTS}

We thank William Eberhard, Linden Higgins, and two anonymous reviewers for their comments on previous versions of this manuscript. We also thank Diana Galindo for lending us the fan for the field experiments, the Organization for Tropical Studies for logistic support, and Don Pedro Gaspar for kindly allowing us to work in his plantation. This investigation was partially supported by the Vicerrectoría de Investigación, Universidad de Costa Rica.

\section{LITERATURE CITED}

Barrantes, G. \& R. Madrigal-Brenes. 2008. Ontogenetic changes in the web and growth of Tengella radiata (Araneae, Tengellidae). Journal of Arachnology 36:545-551.

Barrantes, G. \& W.G. Eberhard. 2010. Ontogeny repeats phylogeny in Steatoda and Latrodectus spiders. Journal of Arachnology $38: 485-494$

Blackledge, T.A. \& C.Y. Hayashi. 2006. Silken toolkits: biomechanics of silk fibers spun by the orb web spider Argiope argentata (Fabricius 1775). Journal of Experimental Biology 209:2452-2461.

Blackledge, T.A. \& J.M. Zevenbergen. 2006. Mesh width influences prey retention in spider orb webs. Ethology 112:1194-1201.

Comstock, J.H. 1912. The Spider Book. Comstock Publishing Associates, Cornell University Press, New York.

Denny, M. 1976. The physical properties of spider's silk and their role in the design of orb-webs. Journal of Experimental Biology 65:483-506.

Eberhard, W.G. 1985. The "sawtoothed" orb web of Eustala sp. (Araneae, Araneidae) with discussion of ontogenetic changes in spiders' web-building behavior. Psyche 92:105-117.

Eberhard, W.G. 1990. Function and phylogeny of spider webs. Annual Review Ecology and Systematics 21:341-372.

Eberhard, W.G., G. Barrantes \& R. Madrigal-Brenes. 2008. Vestiges of an orb-weaving ancestor? The "biogenic law" and ontogenetic changes in the webs and building behavior of the black widow spider Latrodectus geometricus (Araneae: Theridiidae). Ethology Ecology and Evolution 20:211-244.

Harmer, A.M.T., T.A. Blackledge, J.S. Madin \& M.E. Herberstein. 2011. High-performance spider webs: integrating biomechanics, ecology and behaviour. Journal of the Royal Society Interface 8:457-471.

Higgins, L. 1992. Developmental changes in barrier web structure under different levels of predation risk in Nephila clavipes (Araneae: Tetragnathidae). Journal of Insect Behavior 5:635-655.

Hingston, R.W.G. 1992. The snare of the giant wood spider (Nephila maculata), part III: further lessons of the Nephila. Journal of the Bombay Natural History Society 28:917-923. 
Japyassú, H.F. \& C. Ades. 1998. From complete orb to semi-orb webs: developmental transitions in the web of Nephilengys cruentata (Araneae: Tetragnathidae). Behaviour 135:931-956.

Kuntner, M., C.R. Haddad, G. Aljančič \& A. Blejec. 2008a. Ecology and web allometry of Clitaetra irenae, an arboricolous African orbweaving spider (Araneae, Araneoidea, Nephilidae). Journal of Arachnology 36:583-594.

Kuntner, M., J.A. Coddington \& G. Hormiga. 2008b. Phylogeny of extant nephilid orb-weaving spiders (Araneae, Nephilidae): testing morphological ethological homologies. Cladistics 24:147-217.

Lubin, Y.D. 1975. Stabilimenta and barrier webs in the orb webs of Argiope argentata (Araneae, Araneidae) on Daphne and Santa Cruz Islands, Galapagos. Journal of Arachnology 2:119-126.
Masters, W.M. \& A.J.M. Moffat. 1983. A functional explanation of top-bottom asymmetry in vertical orbwebs. Animal Behaviour 31:1043-1046.

Opell, B.D., B.J. Markley, C.D. Hannum \& M.L. Hendricks. 2008. The contribution of axial fiber extensibility to adhesion of viscous capture threads spun by orb-weaving spiders. Journal of Experimental Biology 211:2243-2251.

Robinson, M.H. \& B. Robinson. 1973. Ecology and behavior of the giant wood spider Nephila maculata (Fabricius) in New Guinea. Smithsonian Contributions to Zoology 149:1-76.

Manuscript received 11 April 2011, revised 29 September 2011. 